OPEN ACCESS

Edited by:

Peter Mullany,

University College London,

United Kingdom

Reviewed by:

Ariadnna Cruz-Córdova,

Hospital Infantil de México Federico

Gómez, Mexico

D. Ipek Kurtboke,

University of the Sunshine Coast,

Australia

Maria Soledad Ramirez, California State University, Fullerton,

United States

*Correspondence:

Heejoon Myung

himyung@hufs.ac.kr

Specialty section

This article was submitted to

Antimicrobials, Resistance and

Chemotherapy,

a section of the journal

Frontiers in Microbiology

Received: 07 November 2017

Accepted: 26 March 2018

Published: 10 April 2018

Citation:

Cha K, Oh HK, Jang JY, Jo Y, Kim WK, Ha GU, Ko KS and Myung $H$ (2018) Characterization of Two Novel

Bacteriophages Infecting

Multidrug-Resistant (MDR)

Acinetobacter baumannii and

Evaluation of Their Therapeutic Efficacy in Vivo.

Front. Microbiol. 9:696.

doi: 10.3389/fmicb.2018.00696

\section{Characterization of Two Novel Bacteriophages Infecting Multidrug-Resistant (MDR) Acinetobacter baumannii and Evaluation of Their Therapeutic Efficacy in Vivo}

Kyoungeun Cha ${ }^{1,2}$, Hynu K. Oh ${ }^{1}$, Jae Y. Jang ${ }^{1}$, Yunyeol Jo ${ }^{1}$, Won K. Kim ${ }^{1}$, Geon U. Ha ${ }^{1}$, Kwan S. $\mathrm{Ko}^{3}$ and Heejoon Myung ${ }^{1,2 *}$

${ }^{1}$ Department of Bioscience and Biotechnology, Hankuk University of Foreign Studies, Yong-In, South Korea, ${ }^{2}$ The Bacteriophage Bank of Korea, Hankuk University of Foreign Studies, Yong-In, South Korea, ${ }^{3}$ Samsung Medical Center, Sungkyukwan University School of Medicine, Suwon, South Korea

Acinetobacter baumannii is emerging as a challenging nosocomial pathogen due to its rapid evolution of antibiotic resistance. We report characterization of two novel bacteriophages, PBAB08 and PBAB25, infecting clinically isolated, multidrug-resistant (MDR) A. baumannii strains. Both phages belonged to Myoviridae of Caudovirales as their morphology observed under an electron microscope. Their genomes were double stranded linear DNAs of 42,312 base pairs and 40,260 base pairs, respectively. The two phages were distinct from known Acinetobacter phages when whole genome sequences were compared. PBAB08 showed a 99\% similarity with 57\% sequence coverage to phage $A B 1$ and PBAB25 showed a 97\% similarity with $78 \%$ sequence coverage to phage IME_AB3. BLASTN significant alignment coverage of all other known phages were $<30 \%$. Seventy six and seventy genes encoding putative phage proteins were found in the genomes of PBAB08 and PBAB25, respectively. Their genomic organizations and sequence similarities were consistent with the modular theory of phage evolution. Therapeutic efficacy of a phage cocktail containing the two and other phages were evaluated in a mice model with nasal infection of MDR A. baumannii. Mice treated with the phage cocktail showed a 2.3-fold higher survival rate than those untreated in 7 days post infection. In addition, 1/100 reduction of the number of $A$. baumannii in the lung of the mice treated with the phage cocktail was observed. Also, inflammatory responses of mice which were injected with the phage cocktail by intraperitoneal, intranasal, or oral route was investigated. Increase in serum cytokine was minimal regardless of the injection route. A 20\% increase in IgE production was seen in intraperitoneal injection route, but not in other routes. Thus, the cocktail containing the two newly isolated phages could serve as a potential candidate for therapeutic interventions to treat $A$. baummannii infections.

Keywords: multidrug-resistance, Acinetobacter baumannii, bacteriophage therapy, mouse model, genome analysis 


\section{INTRODUCTION}

Acinetobacter baumannii is an opportunistic pathogen causing nosocomial infection in hospitals. It is designated as an ESKAPE (Enterococcus faecium, Staphylococcus aureus, Klebsiella pneumonia, A. baumannii, Pseudomonas aeruginosa, and Enterobacter species) pathogen by World Health Organization (WHO) (McConnell et al., 2013). It causes mainly pneumonia and additionally burn infections, meningitis, urinary tract infections, and sepsis (Dijkshoorn et al., 2007). Antibioticresistant strains are rapidly emerging and even multidrugresistant (MDR) and pandrug-resistant (PDR) strains are observed (Tuon et al., 2015). Its virulence factors include porins, lipopolysaccharides, capsular polysaccharides, metal acquisition systems, phospholipases, outer membrane vesicles, and protein secretion systems (Weber et al., 2016; Lee et al., 2017). Factors influencing antibiotic resistance includes two-component systems AdeRS, BaeSR, GacSA, and PmrAB (Kröger et al., 2017). Treatment of carbapenem-resistant A. baumannii (CRAB) involves the use of combinations of last resort agents including colistin and tigecycline, but the efficacy and safety issues are not cleared yet (Doi et al., 2015).

Phage therapy is a promising tool for controlling drugresistant bacteria (Abedon, 2017; Lin et al., 2017). The mechanism of drug-resistance is totally unrelated to that of phage infection. Although bacteriophages have been used as an antibacterial for almost 100 years, mainly in eastern European countries, they are not recognized as drugs due to the lack of a proper documentation needed for drug approval. In addition, we still wait for fulfillment of regulatory affairs to approve phage drugs (Huys et al., 2013).

Novel therapies including bacteriophages against drugresistant $A$. baumannii have been reported and reviewed (Mihu and Martinez, 2011; García-Quintanilla et al., 2013; Parasion et al., 2014). Successful phage control of various strains of Acinetobacter was demonstrated not only in vitro but also in vivo. Two newly isolated phages infecting A. baumannii were characterized and suggested as potential candidates for phage cocktail (Merabishvili et al., 2014). Other two newly isolated phages were characterized at genomic DNA level and suggested as potential candidate for phage cocktail against CRAB (Jeon et al., 2016a). Phage BФ-C62 was used to successfully control CRAB infection via nasal route in mice model (Jeon et al., 2016b). Phage $v B$-GEC_Ab-M-G7 was used to successfully control wound infection in a rat model (Kusradze et al., 2016). Medes et al. tested phage cocktails against diabetic cutaneous wounds in two animal models. Phage cocktails for Staphylococcus aureus or Pseudomonas aeruginosa improved wound healing, but cocktail for A. baumannii was not as effective. A personalized phage cocktail for treating mouse dorsal wound model was reported (Regeimbal et al., 2016). Phages from multi-institute libraries were used to make a personalized cocktail and proven effective for treating a diabetic human patient with necrotizing pancreatitis complicated by an MDR A. baumannii infection (Schooley et al., 2017). A phage was effective in resolving wound infection caused by multidrug-resistant A. baumannii in an uncontrolled diabetic rat model (Shivaswamy et al., 2015).
A bacteriophage-containing aerosol was proven effective for cleaning and decreased the rates of infection caused by CRAB in intensive care units (Wang et al., 2016). A combined lysis spectrum of four lytic phages against clinically isolated CRAB was reported to be $87.5 \%$ and phages were proven effective as therapeutic agents for lung infection without deleterious side effects in mice model (Hua et al., 2018).

Here, we report both microbiological characterization of novel phages infecting A. baumannii and the efficacy of a phage cocktail containing the phages in control of nasal infection in a mice model. Further, we provide the basis why the phages can be used as a therapeutic intervention practically.

\section{MATERIALS AND METHODS}

\section{Ethics Statement}

All animal studies were approved by and followed the guidelines and regulations of the Ethical Committee for Animal Experiments of Hankuk University of Foreign Studies (approval number 2017-0001).

\section{Bacterial Strains and Phages Used}

Fourteen clinical A. baumannii strains were obtained from patients in Samsung Medical Center, Sungkyukwan University School of Medicine. Antibiotic resistance profile of the strains is shown in Table 1. To determine the genotypes of the A. baumannii isolates, Oxford scheme multilocus sequence typing (MLST) was performed as described previously (Bartual et al., 2005; http://pubmlst.org/abaumannii/info/primers_ Oxford.shtml). One of the strains (strain 28) was selected and further used for mice experiment. It was resistant to both kanamycin (3.5 mg/ml, Sigma, USA) and ampicillin $(5 \mathrm{mg} / \mathrm{ml}$, Sigma, USA), and this fact was used to enumerate recovered bacteria from mice lung. The 9 bacteriophages tested against the 14 strains were PBAB05, PBAB06, PBAB07, PBAB08, РBAB25, PBAB68, PBAB80, PBAB87, and PBAB93. Bacteriophages used for making the therapeutic cocktail were PBAB08, PBAB25, PBAB68, PBAB80, PBAB93 (Bacteriophage Bank of Korea).

\section{Phage Isolation and Purification}

Bacteriophage isolation and characterization were described thoroughly (Clokie and Kropinski, 2009a,b; Clokie et al., 2018). The isolation and characterization of phages have been described previously (Kim et al., 2013). The phages were purified using a glycerol gradient centrifugation method (Sambrook and Russell, 2006). A single plaque was used to inoculate $5 \mathrm{ml}$ of a mid-exponential-phase culture of the bacterium, followed by incubation at $37^{\circ} \mathrm{C}$ for $3 \mathrm{~h}$. A phage lysate was obtained by centrifugation at $11,000 \mathrm{xg}$ for $10 \mathrm{~min}$ and discarding the supernatant. Five $\mathrm{ml}$ of the lysate was used to inoculate $100 \mathrm{ml}$ of a mid-exponential-phase culture of the bacterium, and the mixture was then incubated until lysis was completed. $\mathrm{NaCl}$ was added to the lysate at a final concentration of $1 \mathrm{M}$, and it was incubated at $4^{\circ} \mathrm{C}$ for $1 \mathrm{~h}$. After centrifugation at $11,000 \mathrm{x} \mathrm{g}$ for $10 \mathrm{~min}, 10 \%$ (wt/vol) polyethylene glycol 8000 (PEG 8000) was added, and the mixture was then incubated at $4^{\circ} \mathrm{C}$ for $1 \mathrm{~h}$. 
TABLE 1 | Antibiotic resistance profile of clinically isolated Acinetobacter baumannii strains and their phage susceptibility.

\begin{tabular}{|c|c|c|c|c|c|c|c|c|c|c|c|c|c|c|}
\hline $\begin{array}{l}\text { Antibiotics/ } \\
\text { name of isolate }\end{array}$ & 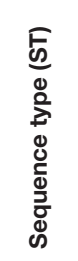 & 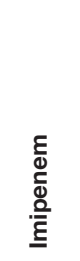 & 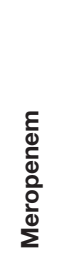 & 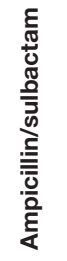 & 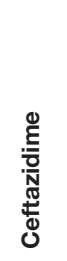 & $\frac{\stackrel{\oplus}{E}}{\frac{\Xi}{0}}$ & $\frac{\frac{c}{0}}{\frac{0}{E}}$ & 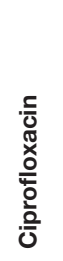 & 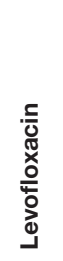 & 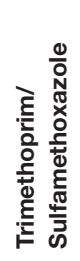 & 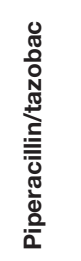 & $\begin{array}{l}\text { 등 } \\
\text { 号 } \\
0\end{array}$ & 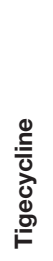 & $\begin{array}{l}\text { PBAB number* of } \\
\text { infecting phages }\end{array}$ \\
\hline Strain 21 & 191 & $>64^{* *}$ & $>64$ & $>64$ & $>64$ & $>64$ & $>64$ & $>64$ & 64 & $>64$ & $>256$ & 1 & 8 & none \\
\hline Strain 32-a & 191 & $>64$ & $>64$ & $>64$ & $>64$ & $>64$ & $>64$ & $>64$ & $>64$ & $>64$ & $>256$ & 1 & 8 & none \\
\hline Strain F-224 & 1240 & $>64$ & $>64$ & $>64$ & $>64$ & $>64$ & $>64$ & $>64$ & $>32$ & $>64$ & $>256$ & 1 & 8 & $5,6,7,87$ \\
\hline Strain F-1208 & 357 & $>64$ & $>64$ & $>64$ & $>64$ & $>64$ & $>64$ & $>64$ & 32 & $>64$ & $>256$ & $>64$ & 1 & $8,68,80,93$ \\
\hline Strain F-1510 & 191 & $>64$ & $>64$ & $>64$ & $>64$ & $>64$ & $>64$ & $>64$ & 16 & $>64$ & $>256$ & 2 & 8 & none \\
\hline Strain F-1629 & 357 & $>64$ & $>64$ & 32 & $>64$ & 64 & $>64$ & $>64$ & 32 & $>64$ & $>256$ & $>64$ & 8 & $8,68,80,93$ \\
\hline Strain 26 & 368 & 16 & 16 & 32 & 64 & 64 & 16 & 4 & 32 & 32 & 128 & 64 & 4 & $8,68,80$ \\
\hline Strain 28 & 368 & 16 & 16 & 16 & 64 & 64 & 16 & 4 & 32 & 32 & 128 & 1 & 8 & $8,25,68,80,93$ \\
\hline Strain 32-b & 357 & 16 & 16 & 16 & 64 & 64 & 16 & 4 & 32 & 32 & 128 & 4 & 2 & $8,68,80,93$ \\
\hline Strain 54 & 208 & 16 & 16 & 32 & 64 & 64 & 16 & 4 & 8 & 32 & 128 & 1 & 2 & none \\
\hline Strain 58 & 208 & 16 & 16 & 32 & 64 & 64 & 16 & 4 & 8 & 32 & 128 & 1 & 2 & none \\
\hline Strain 81 & 191 & 16 & 16 & 32 & 64 & 64 & 16 & 4 & 8 & 32 & 128 & 4 & 4 & $5,6,7,87$ \\
\hline Strain K20-B-667 & 191 & $>64$ & $>64$ & $>64$ & $>64$ & $>64$ & $>64$ & $>64$ & $>64$ & $>64$ & $>256$ & 1 & 8 & none \\
\hline Strain K20-B-890 & 191 & 8 & 64 & $>64$ & 32 & 64 & $>64$ & $>64$ & $>64$ & $>64$ & 256 & 1 & 32 & none \\
\hline
\end{tabular}

${ }^{*} P B A B$ numbers according to the Bacteriophage Bank of Korea (www.phagebank.or.kr).

${ }^{\star \star} T$ The numbers in each box shows the maximum concentration of each antibiotic to which tested bacteria was resistant (mg/L).

Darkly shaded box means "resistant", lightly shaded box "intermediate", and white box "susceptible".

The supernatant was discarded after centrifugation at $11,000 \mathrm{x}$ $\mathrm{g}$ for $10 \mathrm{~min}$. Then the pellet was resuspended in $750 \mu \mathrm{l}$ of $\mathrm{SM}$ buffer [ $100 \mathrm{mM} \mathrm{NaCl}, 8 \mathrm{mM} \mathrm{MgSO} 4 \cdot 7 \mathrm{H}_{2} \mathrm{O}, 50 \mathrm{mM}$ Tris-Cl ( $\mathrm{pH} 7.5)$, and chloroform was added at a ratio of $1: 1$ ( $\mathrm{vol} / \mathrm{vol})$, followed by vortexing and then centrifugation at 3,000x g for $15 \mathrm{~min}$. The upper phase was isolated and was added to a polycarbonate centrifuge tube containing $3 \mathrm{ml}$ of $40 \%$ glycerol in the lower layer and $4 \mathrm{ml}$ of $5 \%$ glycerol in the upper layer. After centrifugation at $151,000 \mathrm{x}$ g for $1 \mathrm{~h}$, the supernatant was discarded, and the pellet was resuspended in $400 \mu$ l of SM buffer. For animal experiments, any contaminating lipopolysaccharide (LPS) was removed before treatment. Triton X-114 (Sigma, USA) was added to phage solution at a final concentration of $1 \%$ (vol/vol) and mixed using vortex for $10 \mathrm{~s}$. After incubation on ice for $10 \mathrm{~min}$, the mixture was transferred to $37^{\circ} \mathrm{C}$ water bath and incubated for $1 \mathrm{~min}$. After a centrifugation at $15,000 \mathrm{x} \mathrm{g}$ for $5 \mathrm{~min}$, supernatant was collected and used as the final phage solution. Purified phages were stored at $4^{\circ} \mathrm{C}$ until use. Standard double agar overlay plaque technique was used for phage enumeration (Kropinski et al., 2009).

\section{Transmission Electron Microscopy (TEM) of Phage Particles}

Purified phage sample was loaded onto a copper grid for $1 \mathrm{~min}$ followed by negative staining with $2 \%$ (vol/vol) uranyl acetate (pH 6.7) and drying. The phage morphology was observed using a Carl Zeiss LIBRA 120 EF-TEM (Carl Zeiss, Oberkochen, Germany) at an accelerating voltage of $120 \mathrm{kV}$.

\section{Genome Sequencing, Annotation, and Analysis}

Whole genome sequencing of phage DNA was carried out using PacBio RS II system in Macrogen, Korea. Open reading frames (ORFs) were searched using NCBI ORF Finder. Genomic sequence similarity comparison was done using MAUVE. ORF map was drawn using CLC Genomics Workbench 10. Genomic tree was drawn using Mega 7.

\section{One Step Multiplication}

One step growth experiment was described previously (Hyman and Abedon, 2009). Briefly, phage PBAB08 or PBAB25 was added to a fresh culture of A. baumannii at an MOI 0.001 and allowed to adsorb for $5 \mathrm{~min}$. The mixture was then centrifuged at 1,738 $\mathrm{xg}$ for $10 \mathrm{~min}$. The supernatant was discarded to remove any free phages and the pellet was resuspended in $3 \mathrm{ml}$ of fresh LB broth incubated at $37^{\circ} \mathrm{C}$ with shaking. One hundred micro liters of sample was removed from the culture every $5 \mathrm{~min}$ and subjected to titration using double-layer agar plate methods (Kropinski et al., 2009). This assay was performed at least in triplicate.

\section{Phage Stability}

For temperature stability test, phage titer was measured after incubation of phage lysates for $1 \mathrm{~h}$ at different temperatures (4, $37,45,55,60,65$, or $80^{\circ} \mathrm{C}$ ) using a double-layer agar plate method (Kropinski et al., 2009). For pH stability test, phage titer was measured after 1 h's incubation of phage lysates at room temperature by mixing with equal volume of $\mathrm{pH}$ buffer solutions of different $\mathrm{pH}$ values ( $\mathrm{pH} 3,4,5,6,7,8,9,10$, and 11). $\mathrm{pH}$ 
buffer solutions were made by adding $\mathrm{HCl}$ drop by drop to $1 \mathrm{M}$ $\mathrm{NaOH}$ solution. The resulting $\mathrm{pH}$ was measured using S220 seven compact $^{\mathrm{TM}} \mathrm{pH} /$ Ion (Mettler Toledo, Columbus, USA).

\section{Phage Protection Studies Using a Mice Model}

Six week-old female Balb/c mice were obtained from Young Bio, Korea. Mice were divided into 4 groups; Group 1 was treated with SM buffer only. Group 2 was infected with MDR A. baumannii (strain 28) only. Group 3 was treated with the phage cocktail only. Group 4 was infected with A. baumannii and treated with the phage cocktail. Each group contained 20 mice. Mice were intraperitoneally injected with cyclophosphamide (Sigma, USA) at the concentration of $150 \mathrm{mg} / \mathrm{kg}$ at -1 and -3 days of bacterial infection. Before intranasal bacterial or phage injection, mice were anesthetized with $125 \mathrm{mg} / \mathrm{kg}$ of avertin (Sigma, USA) by intraperitoneal injection. $1 \times 10^{8} \mathrm{CFU}$ of $A$. baumannii was intranasally injected to each mouse at 0 and +1 days. SM buffer was injected to the control group mice instead. $1 \times 10^{9} \mathrm{PFU}$ of phage cocktail was intranasally injected to experimental mice every day from -1 to +7 days. At days 0 and +1 , phages were injected $4 \mathrm{~h}$ after bacterial injection. Survival of mice was observed until 7 days after bacterial infection. Bacterial load in mice lung was counted as follows; lung was isolated at +3 and +4 days and weight was measured. After homogenization, 500 $\mu l$ of SM buffer was added and was subjected to centrifugation at 2,000x g. The supernatant was used for counting A. baumannii in a medium containing both kanamycin $(3.5 \mathrm{mg} / \mathrm{ml})$ and ampicillin $(5 \mathrm{mg} / \mathrm{ml})$.

\section{Cytokine, IgE, and Histamine Assays}

To see immune reactions against phages, the cocktail was introduced every day for 7 days to mice in three different routes; intraperitoneal, intranasal, and oral. Three mice were used for each route. Control group was treated with SM buffer. One day after the last treatment of a phage cocktail, mice were sacrificed and serum was obtained for analysis of cytokine profile using Multi-Analyte ELISArray kits (Qiagen, USA), of IgE profile using RayBio ${ }^{\circledR}$ Mouse IgE ELISA Kit (RayBiotech, USA), and of histamine using Histamine Enzyme Immunoassay Kit (SPI Bio, France).

\section{Statistical Analyses}

Student's $t$-test (Bailey, 1959) was used to calculate the significance of the difference among test groups. For each assay, all determinations were carried out at least in triplicate. Statistically significant values were defined as $P<0.05$ or $P<0.01$

\section{RESULTS}

\section{Antibiotic Resistance of Clinically Isolated A. baumannii Strains}

Fourteen bacterial isolates were selected and their antibiotic resistance and phage susceptibility were observed (Table 1). All the isolates were multidrug-resistant (MDR) strains. Many of them were resistant even to colistin or tigecycline. The
14 A. baumannii isolates showed five sequence types (STs) based on MLST (Table 1), and they belonged to the same clonal complex (CC), global complex II. Nine Acinetobacter bacteriophages, PBAB05, PBAB06, PBAB07, PBAB08, PBAB25, PBAB68, PBAB80, PBAB87, and PBAB93, were selected from the Bacteriophage Bank of Korea and tested for infection to the clinical A. baumannii strains. Seven out of 14 isolates could be infected by four or five phages. The phage susceptibility was not related to antibiotic resistance profile. Isolate 28 was susceptible to all five phages and thus selected for mice infection experiments later. We further characterized two of the phages PBAB08 and PBAB25 from which whole genomic DNA sequences were successfully obtained as single contigs after next generation sequencing.

\section{Bacteriophage Characterization}

Two phages, PBAB08 and PBAB25, belonged to family Myoviridae of order Caudovirales (Figures 1A,B). Their virions were composed of a spherical head and a long, rigid tail. Phage PBAB08 had a head of $180 \mathrm{~nm}$ in diameter and a tail of $360 \mathrm{~nm}$ in length. The smaller phage PBAB25 had a head of $80 \mathrm{~nm}$ in diameter and a tail of $90 \mathrm{~nm}$ in length. A complete lysis of host bacteria infected with PBAB08 or PBAB25 occurred in $25 \mathrm{~min}$ post infection (Figure 1C). Burst size for each phage was 215 and 630 , respectively.

The infectivity of PBAB08 and PBAB25 remained intact when exposed to pHs ranging from 5 to 10 for $1 \mathrm{~h}$ (Figures 2A,B). It decreased rapidly at $\mathrm{pHs}$ above 10 . The infectivity of both phages remained intact when exposed to temperatures ranging from 4 to $55^{\circ} \mathrm{C}$ for $1 \mathrm{~h}$ and dropped rapidly above $65^{\circ} \mathrm{C}$ (Figures 2C,D).

\section{Genomic Sequence Analysis}

The whole genomes of phages PBAB08 and PBAB25 were sequenced (GenBank accession numbers MG366114 and MG366115, respectively). Their genomes were double stranded linear DNAs of 42,312 base pairs and 40,260 base pairs, respectively. The genome sequences were compared to reported Acinetobacter phages using BLASTN. PBAB08 showed a $99 \%$ similarity with $57 \%$ sequence coverage to phage AB1 (Yang et al., 2010), and PBAB25 showed a 97\% similarity with $78 \%$ sequence coverage to phage IME_AB3 (Zhang et al., 2015). BLASTN significant alignment coverage of all other known phages were $<30 \%$. A mosaic structure between the genomes of PBAB08 and AB1, and that of PBAB25 and IME_AB3 were observed (Figure 3). An extensive rearrangement occurred between genomes of PBAB08 and AB1, while genomic structure was conserved between PBAB25 and IME_AB3.

Seventy six and seventy genes encoding phage proteins were found in the genomes of $\mathrm{PBAB} 08$ and $\mathrm{PBAB} 25$, respectively (Figure 4). Functional annotation of putative ORFs of each phage is shown in Tables 2, 3. They are divided into four categories according to functions; structural proteins, those involved in DNA packaging, those involved in replication and regulation, and those involved in lysis. It was evident that sequence similarities for both pairs were more prominent in virion proteins than in proteins involved in replication and regulation. It is not fair to compare virion proteins of the two pairs in parallel 

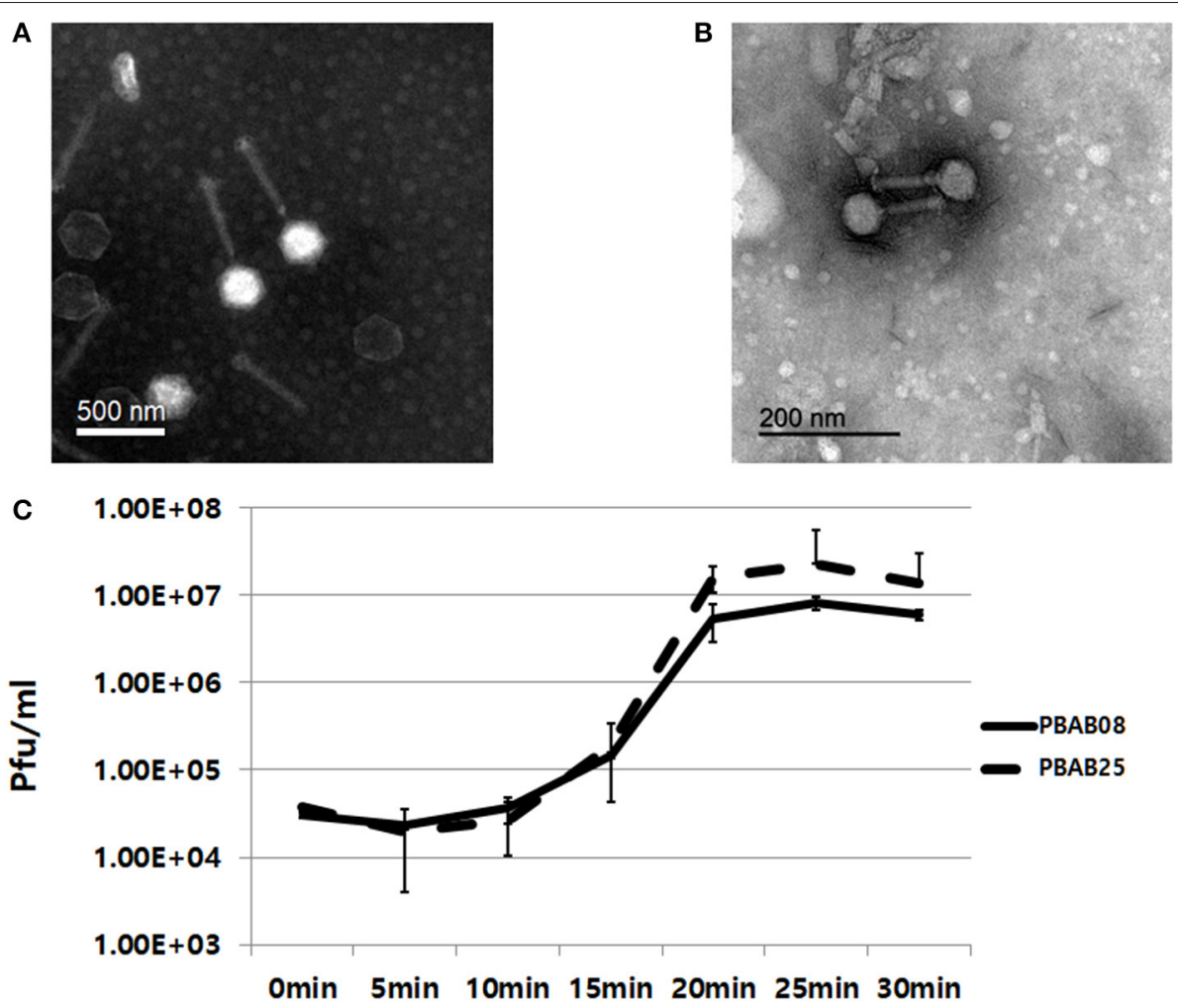

FIGURE 1 | Transmission electron micrographs of bacteriophages PBAB08 (A) and PBAB25 (B). Samples were negatively stained with uranyl acetate. Scale bar is shown in each picture. (C) One step multiplication of phages PBAB08 (solid line) and PBAB25 (broken line).

since the extent of annotations were different. Nevertheless, it is notable that PBAB25 had a wide array of tail proteins suggesting a complicated tail structure. Since both phages had their own putative DNA polymerases, a phylogenetic tree of closely related Acinetobacter phages in GenBank was drawn based on the sequence comparison of their DNA polymerase genes (Figure 5). The phages could be grouped as two, in which PBAB08 belonged to one group (upper 10 phages in Figure 5), while PBAB25 belonged to the other group (lower 10 phages). No DNA polymerase was found in functional annotation of ORFs of phage $A B 1$, thus it was not included in the tree.

\section{In Vivo Efficacy of Phage Cocktail}

Only $15 \%$ of mice infected with $A$. baumannii intranasally survived at 7 days post infection (Figure 6A). On the contrary, $35 \%$ of mice infected with the bacteria followed by treatment with the phage cocktail survived. A better survival of phage-treated mice was observed at day 4 post infection. Sixty percentage of mice survived with phage treatment while $20 \%$ of mice survived with only bacterial infection. Mice treated with phage only remained healthy for the entire experimental period.

Reduction of bacterial load in infected lung of mice was observed (Figure 6B). At 3 and 4 days post bacterial infection, bacteria resistant to both kanamycin and ampicillin were counted. Double-resistant bacterial count was reduced more than 100 -fold for both days. Nevertheless, it was clear that a complete elimination of $A$. baumannii was not achieved with this phage treatment.

\section{Immune Reactions Against the Phage Cocktail}

Phages are foreign substances to mice and there are chances they could elicit immune responses. We checked changes in serum IgE level indicating any allergic responses for three different routes of phage injection (Figure 7A). A 20\% increase in serum IgE was observed for intraperitoneal injection route, while no significant change was observed for either intranasal or oral administration. For cytokines, a slight increase of serum GM-CSF was observed for all three routes of phage administration (Figure 7B). In intraperitoneal route, slight increases of IL2, IL10, and IL17A were also observed. Thus, inflammatory response against the phage cocktail was minimal. No significant change in histamine level was observed when phage cocktail was administered (Supplementary Figure 1).

\section{DISCUSSION}

Among the clinically isolated MDR A. baumannii strains used in this study, some of them were infected by three or more phages, while the others were not infected by any of the five phages used. The degree of drug-resistance of a host bacterium was not related to the number of phages infecting the same 


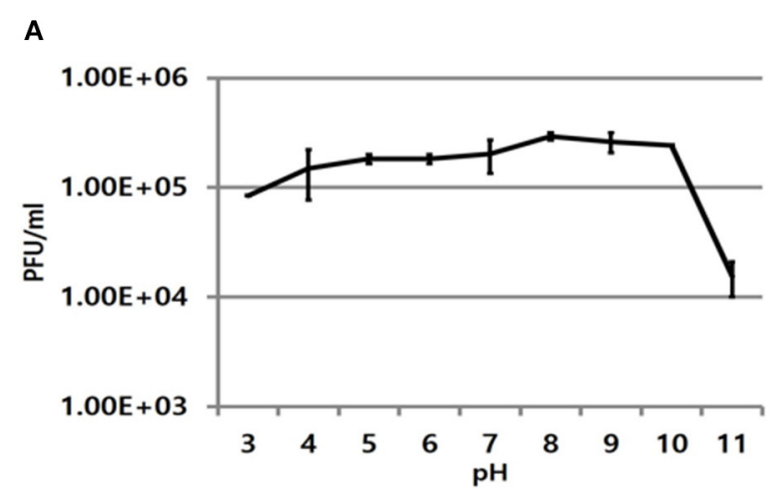

C

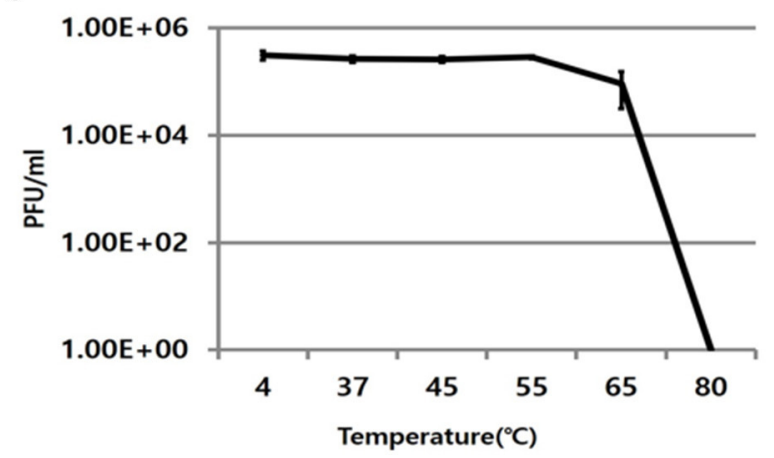

B

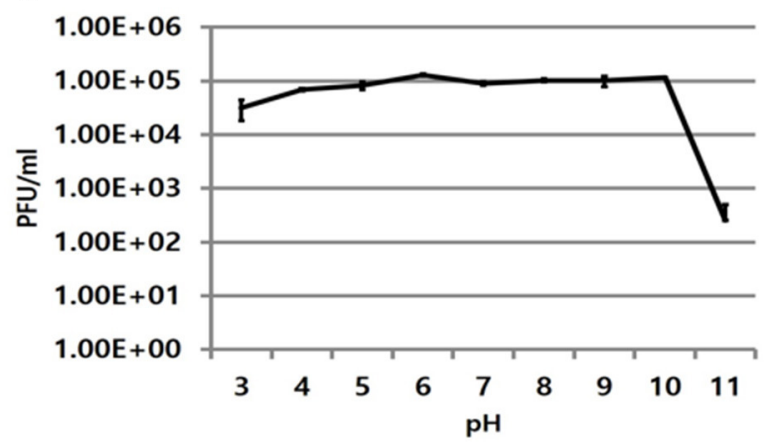

D

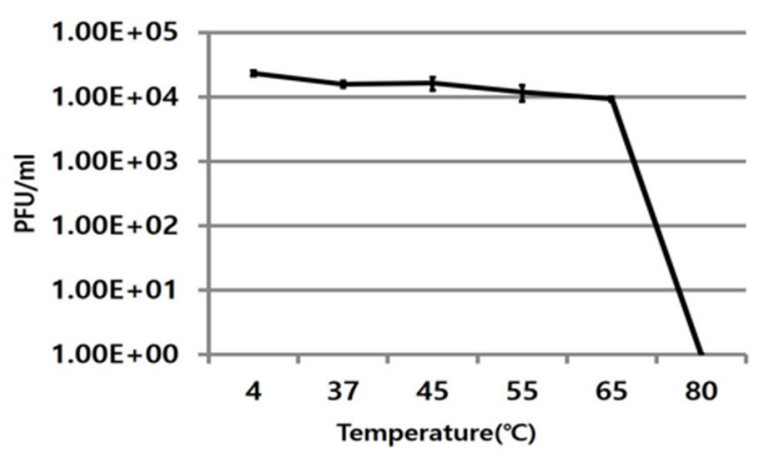

FIGURE 2 | Stability of phages at various pHs and temperatures. Remaining infectivity of phages PBAB08 (A) and PBAB25 (B) were measured after exposure of phages to indicated pHs for $1 \mathrm{~h}$. Remaining infectivity of phages PBAB08 (C) and PBAB25 (D) were measured after exposure of phages to indicated temperatures for $1 \mathrm{~h}$. The experiments were carried out in a triplicate.

Acinetobacter phage PBAB08

\section{Acinetobacter phage $A B 1$}

Acinetobacter phage PBAB25

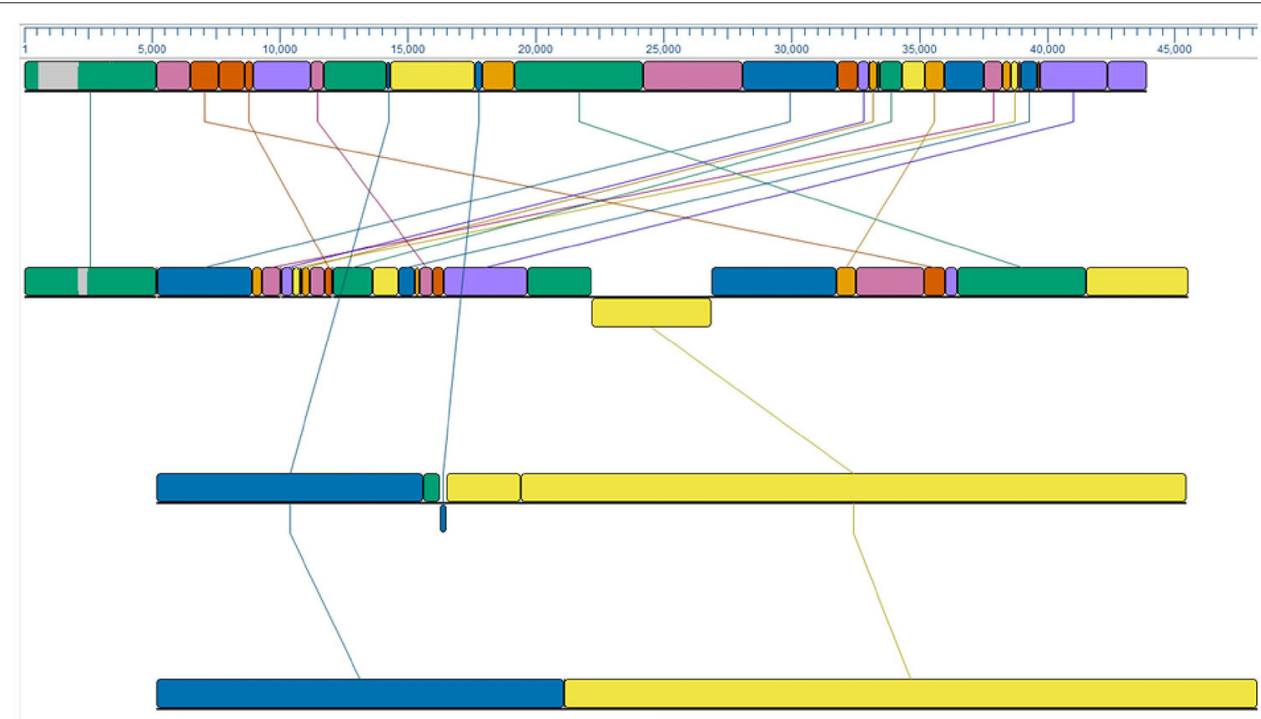

FIGURE 3 | Genomic sequence comparison between phages PBAB08, AB1, PBAB25, and IME_AB3 using MAUVE. Line-connected colored boxes indicate regions of sequence similarity in corresponding phage genomes. 


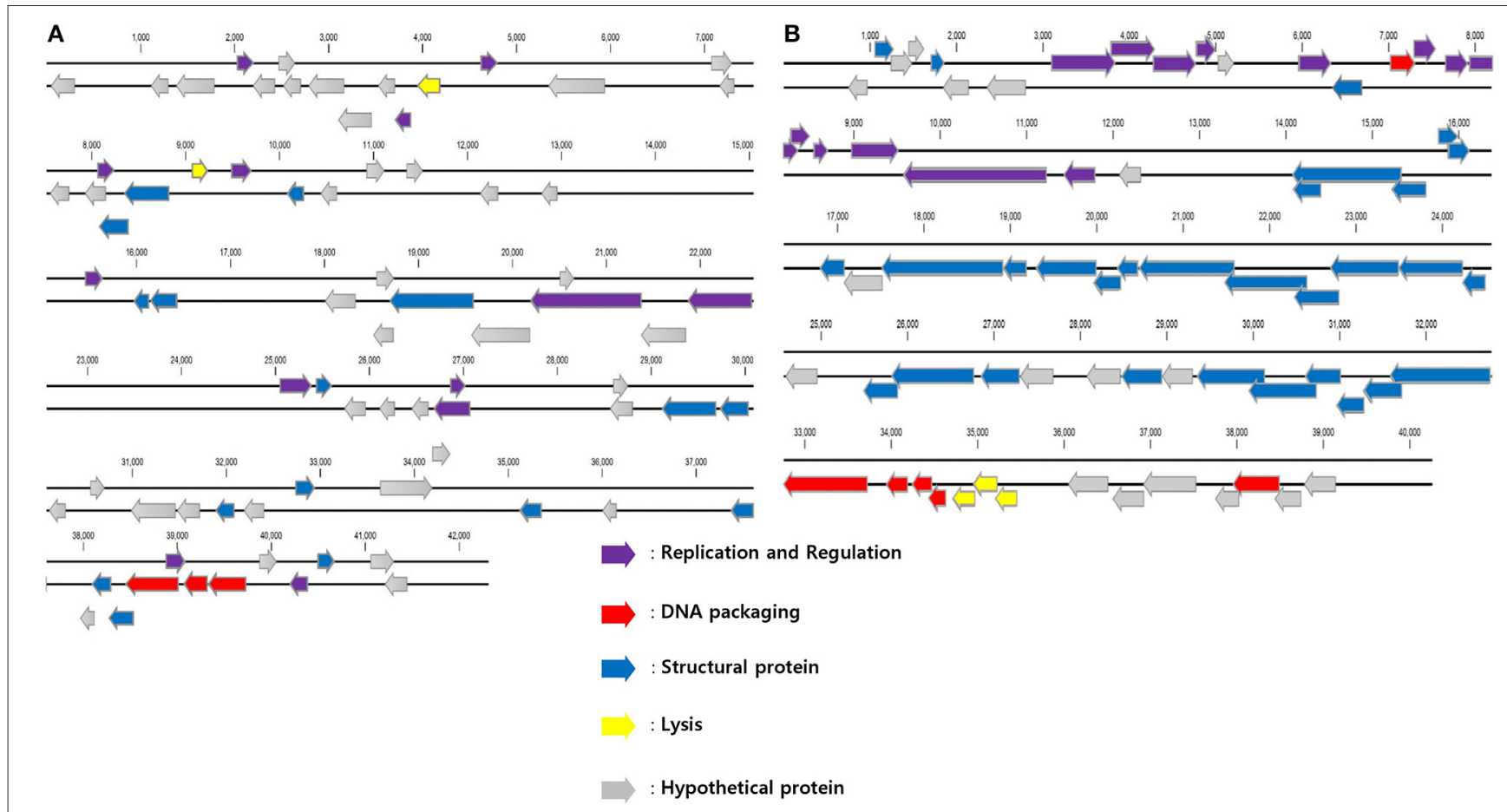

FIGURE 4 | Putative open reading frame (ORF) map of phages PBAB08 (A) and PBAB25 (B). ORF map was drawn using CLC Genomics Workbench 10. Each arrow is color-coded according to annotated genomic function.

host, indicating that acquirement of drug resistance, probably by horizontal gene transfer (Huang et al., 2015; Krahn et al., 2016; Zhang et al., 2017) did not involve alteration of phage receptor or replication mechanisms. It further suggested that MDR bacteria could be treated with phages as long as infecting phages could be isolated.

Head size of PBAB08 $(180 \mathrm{~nm})$ was twice that of PBAB25 $(80 \mathrm{~nm})$. Yet, the lengths of genomic DNAs of the two phages were about the same. For example, the genome size of phage T4 is 169 kilobase pair and the head size varies between 85 and $120 \mathrm{~nm}$ (Keller et al., 1988). Although a minimal requirement should be enough room for containing entire phage genomic DNA, it seems that there are other determinants of the head size of a phage. In the case of T4, head size determinant included scaffolding core and the shell of the procapsid, mutants of which resulted in varied head sizes (Keller et al., 1988).

From $\mathrm{pH}$ and temperature stability data, phage infectivity should remain intact at temperatures and $\mathrm{pHs}$ reaching well outside normal human physiological conditions. This should be a good characteristics if the phages are intended for therapeutic applications. A phage preparation in a suitable buffer kept in a refrigerator could remain stable until it encounters target bacteria when applied in vivo.

A mosaic in genomic structure observed from closely related phages in this study is consistent with the modular theory of phage evolution where phage genomes are mosaics of modules that recombines freely in genetic exchanges involving different phages (Botstein, 1980). It was also observed in other viruses including P2-like phages (Davies and Lee, 2006) and even animal viruses (Botstein, 1980). It is no wonder that viruses evolve rapidly by exchanging genetic materials and extend their diversity. The ease of such exchange in a host cell could be one reason why phages are the most divergent biological entities on earth. In the case of phage $A B 1$ which lacks its own DNA polymerase gene, the phage should depend on host DNA polymerase for its own replication. Still its genome retains genomic mosaic to $\mathrm{PBAB} 08$, suggesting that modular recombination among phage genomes was independent of their replication strategy. It should be noted that DNA polymerases of PBAB25 and phage Presley was closest in sequence, but overall similarity between their genomic sequences was $<30 \%$. It suggests that multiple rounds of recombination events has occurred among various strains of phages during the evolution.

It is noteworthy that only 3 genes encoding putative tail proteins in PBAB08 with a longer tail was annotated while 14 genes annotated in PBAB25 with much shorter tail. It seems that tail length is not related to complexity of its structure. Although electron microscopy of phage IME_AB3, closest to PBAB25 in genomic DNA sequence, was not clear enough to tell the tail structure (Zhang et al., 2015), the two closely related phages of IME_AB3, Acinetobacter phage vB_AbaS_Loki (Turner et al., 2017) and Achromobacter phage phiAxp-1 (Li et al., 2016), have noncontractile tails and are classified as Siphoviridae, while PBAB25 belonged to Myoviridae. Thus it suggests that sequence similarity of tail components does not ensure the similarity in tail morphology. 
TABLE 2 | Functional annotation of putative ORFs found in bacteriophage PBAB08.

\begin{tabular}{|c|c|c|c|c|}
\hline ORF & Function & Related bacteria or phage & Putative encoded phage protein & Similarity (\%) \\
\hline 9 & Structural protein & Acinetobacter phage WCHABP5 & Putative internal virion protein B & 100 \\
\hline 11 & & Acinetobacter phage vB_AbaP_PD-6A3 & Putative internal virion core protein & 91 \\
\hline 33 & & Acinetobacter phage phiAB6 & Putative internal virion protein & 75 \\
\hline 46 & & Acinetobacter phage AB3 & Tail tubular protein B & 100 \\
\hline 56 & & Acinetobacter phage YMC11/12/R2315 & Putative head protein & 92 \\
\hline 61 & & Acinetobacter phage phiAC-1 & Putative capsid protein & 95 \\
\hline 66 & & Acinetobacter phage phiAC-1 & Putative tail fiber protein & 88 \\
\hline 68 & & Acinetobacter phage AB3 & Putative internal virion protein B & 73 \\
\hline 69 & & Acinetobacter phage AB3 & Putative internal virion protein B & 97 \\
\hline 73 & & Acinetobacter phage IME-AB2 & Putative phage head portal protein & 93 \\
\hline 79 & & Acinetobacter bacteriophage AP22 & Putative portal protein & 91 \\
\hline 86 & & Acinetobacter phage phiAC-1 & Putative capsid protein & 95 \\
\hline 99 & & Acinetobacter phage IME-AB2 & Putative phage head portal protein & 95 \\
\hline 100 & & Acinetobacter phage YMC-13-01-C62 & Putative portal protein & 98 \\
\hline 111 & & Acinetobacter phage YMC-13-01-C62 & Putative portal protein & 90 \\
\hline 114 & & Acinetobacter baumannii 99063 & Putative membrane protein & 94 \\
\hline 121 & & Acinetobacter phage WCHABP12 & Putative tail fiber protein & 75 \\
\hline 54 & DNA packaging & Acinetobacter phage IME-AB2 & Putative phage terminase large subunit & 98 \\
\hline 78 & & Acinetobacter phage IME-AB2 & Putative phage terminase large subunit & 93 \\
\hline 110 & & Acinetobacter phage IME-AB2 & Putative phage terminase large subunit & 90 \\
\hline 2 & $\begin{array}{l}\text { Replication and } \\
\text { Regulation }\end{array}$ & Harpegnathos saltator & Apolipoprotein D & 77 \\
\hline 7 & & Acinetobacter phage vB_AbaM_IME200 & DNA polymerase I & 73 \\
\hline 16 & & Stenotrophomonas maltophilia & Adenine phosphoribosyltransferase (fragment) & 63 \\
\hline 20 & & Acinetobacter phage vB_AbaM_IME200 & Carboxypeptidase & 95 \\
\hline 24 & & Massilia sp. JS1662 & Amino acid transporter & 50 \\
\hline 29 & & Staphylococcus aureus subsp. aureus & $\begin{array}{l}\text { Nickel ABC transporter, nickel/metallophore periplasmic } \\
\text { binding domain protein }\end{array}$ & 89 \\
\hline 40 & & Rathayibacter sp. VKM Ac-2630 & Transcriptional regulator & 75 \\
\hline 52 & & Burkholderia sp. WSM4176 & TonB-dependent receptor & 60 \\
\hline 109 & & Acinetobacter phage WCHABP12 & Global DNA-binding transcriptional dual regulator & 87 \\
\hline 116 & & Acinetobacter phage YMC-13-01-C62 & Putative RNA polymerase & 92 \\
\hline 119 & & Acinetobacter phage YMC-13-01-C62 & Putative baseplate assembly protein & 98 \\
\hline 120 & & Acinetobacter phage WCHABP1 & Baseplate J-like protein & 98 \\
\hline 125 & & Acinetobacter phage WCHABP1 & Putative RNA polymerase & 89 \\
\hline 19 & Lysis & Acinetobacter phage WCHABP5 & Putative holin & 51 \\
\hline 74 & & Acinetobacter phage WCHABP5 & Putative holin & 83 \\
\hline
\end{tabular}

More than two-fold increase of survival from mice treated with phage cocktail was shown in this study. Although it proved a limited effectiveness, there could be a room for improvements. In a previous report, mice survival after phage treatment in a nasal infection model was higher than this experiment (Jeon et al., 2016b). But it should be noted that in the same report mice were inoculated with phages only after $30 \mathrm{~min}$ of bacterial infection, in which bacterial proliferation time was much shorter before confronting phages. In this study, there was a $4 \mathrm{~h}$ gap between bacterial infection and phage inoculation. In another report, open wound in rats were treated with phages after A. baumannii infection (Kusradze et al., 2016). Phage treatment was done at $12 \mathrm{~h}$ after bacterial infection, but showed a higher reduction of bacterial load than this study. Depending on types of infection and routes of inoculation, the outcome seems to vary. A pretreatment of phages in this study did not help efficiently eliminating incoming bacteria. Most of the phages could be destabilized and lost their infectivity before bacterial infection. In a wound infection model, loss of phages during application would be less than nasal infection model since there would be less chance of immune-mediated clearance. Also, the amount of phages applied seems to be critical. A dose dependency was observed in a previous report (Jeon et al., 2016b).

Increase in serum proinflammaotry cytokines after phage treatment, if any, could reflect a possible inflammatory response elicited by phages. But it was minimal in this study. Mice remained healthy and behaved normally. The observation is coherent with the previous finding that oral inoculation of T7 
TABLE 3 | Functional annotation of putative ORFs found in PBAB25.

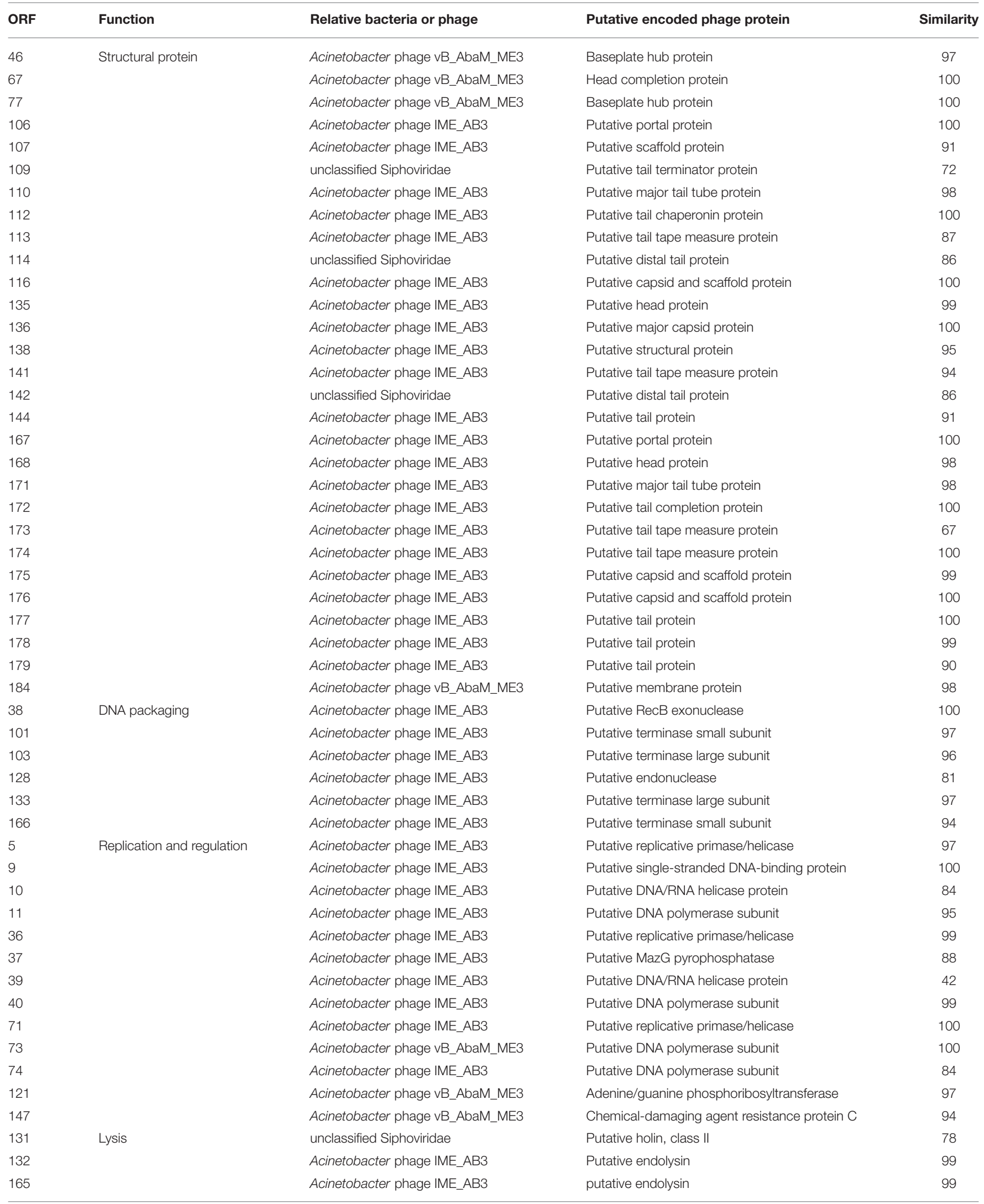




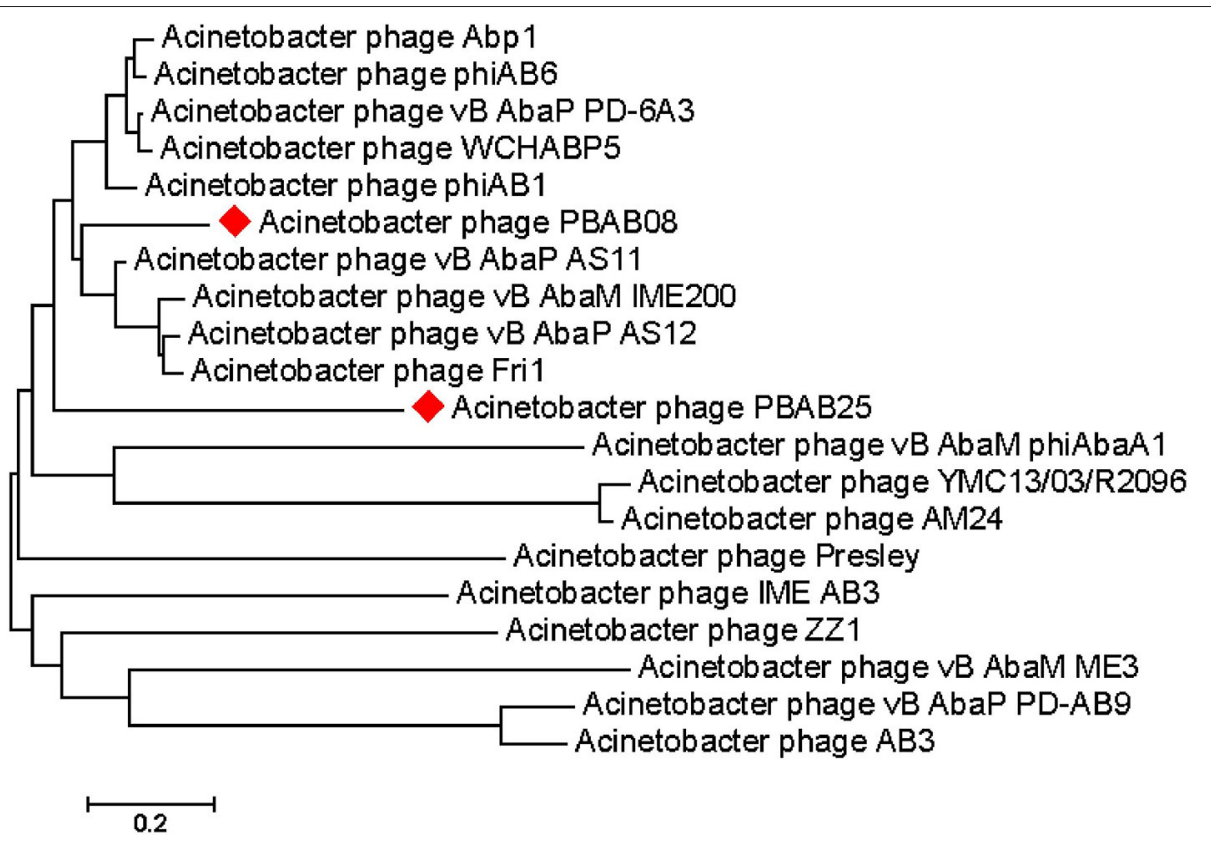

FIGURE 5 | Genomic tree of Acinetobacter phages found in GenBank. The tree was drawn based on each phage's DNA polymerase gene sequence using Mega 7.

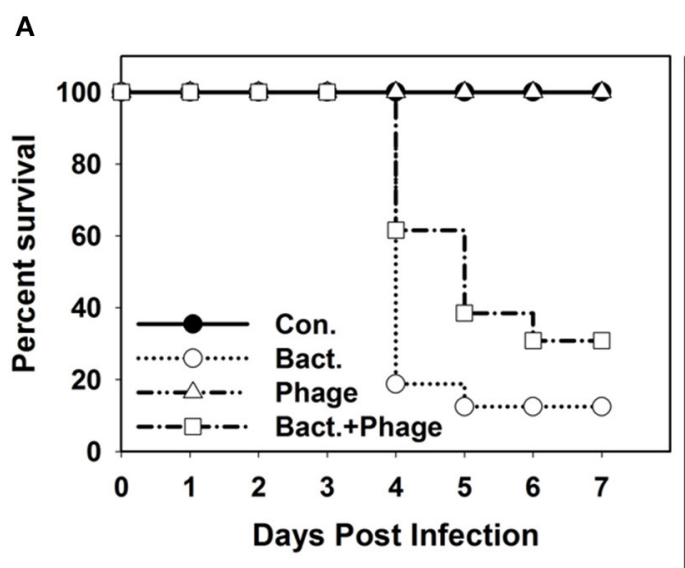

B

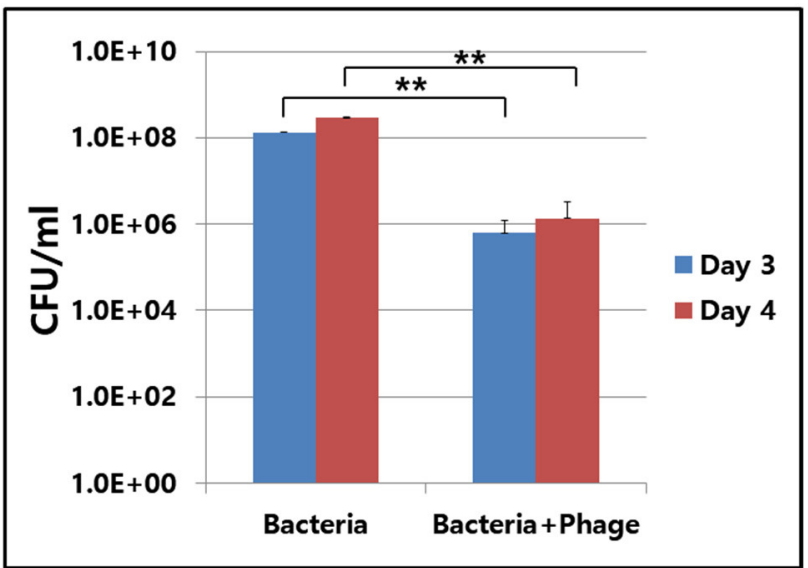

FIGURE 6 | In vivo efficacy of the phage cocktail containing PBAB08 and PBAB25 in a mice nasal infection model. (A) Survival of 4 groups of mice observed for 7 days after bacterial infection. Group 1 (closed circle) was inoculated with SM buffer only. Group 2 (open circle) was infected with MDR A. baumannii strain 28 only. Group 3 (triangle) was treated with the phage cocktail only. Group 4 (rectangle) was infected with A. baumannii and treated with the phage cocktail. (B) Bacterial load in lungs of infected mice in 3 and 4 days post-infection with or without phage treatment. ${ }^{\star \star} P<0.01$.

phages induced a minimal increase in cytokine production of mice (Park et al., 2014). Another phage, SH-Ab 15519, was reported and the therapeutic efficacy was better than the phage cocktail used in this study (Hua et al., 2018). Application of only a single phage showed $90 \%$ survival of mice with the M.O.I of 1 or 10. BLAST search revealed $24 \%$ coverage with $92 \%$ identity when compared to PBAB08, meaning only a low degree of relatedness. As in this study, application of SG-Ab 15519 was generally safe based on histopathological examination of mice lung treated with the phage and cytokine analysis.

Taken together, bacteriophage treatment for mice nasally infected with clinically isolated MDR A. baumannii strain was proven effective and safe. Depending on bacterial strains and phages, an optimal condition for an effective treatment needs to be set. Parameters should include selection of phages from a bank collection based on susceptibility of the causative bacterial strain, composition of a cocktail containing different phage-resistant group members, doses and lengths of phage applications, and routes of phage application. A rapid inoculation of phages after exposure to the pathogen is another critical requirement.

Based on findings that the phage cocktail containing PBAB08 and PBAB25 is effective and safe for treating infections by MDR A. baumannii in vivo, phage therapy would be a viable 

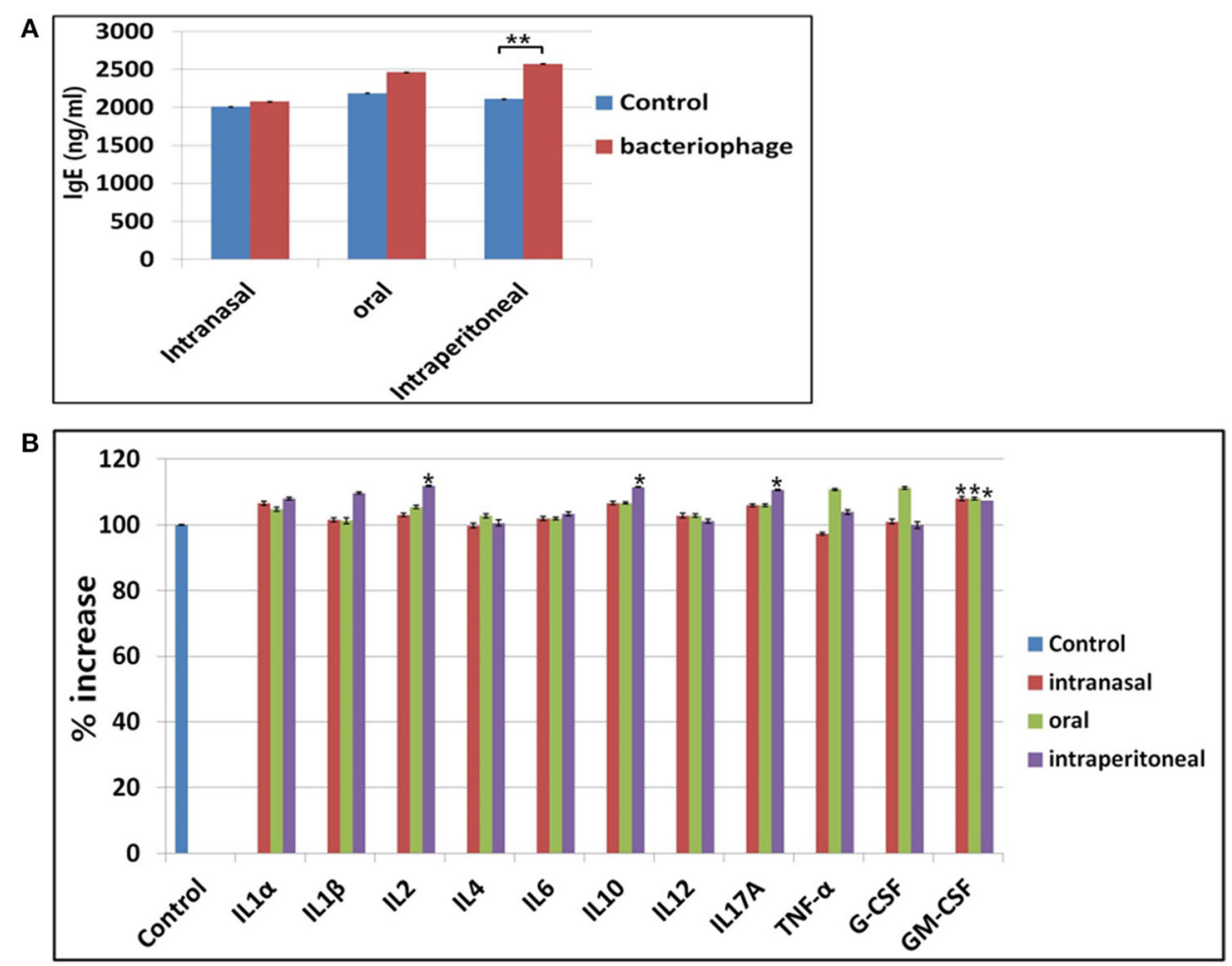

FIGURE 7 | Observation of immune responses against phage treatment in mice. (A) Changes in lgE production after treatment of phages in three different routes. (B) Changes in cytokine production after phage treatment in intranasal, oral, or intraperitoneal route. ${ }^{\star} P<0.05$, ${ }^{\star \star} P<0.01$.

alternative for antibiotics, especially in cases where antibiotics are not treatment options any more.

\section{AUTHOR CONTRIBUTIONS}

HM and KK: designed experiments; KC, YJ, WK, and GH: carried out experiments; $\mathrm{HO}$ and JJ: analyzed experimental results; HM: wrote the manuscript.

\section{FUNDING}

This work was supported by National Research Foundation (NRF) of Korea Funds 2015R1A2A2A01003632 and

\section{REFERENCES}

Abedon, S. T. (2017). Bacteriophage clinical use as antibacterial "drugs": utility and precedent. Microbiol. Spectr. 5:BAD-0003-2016. doi: 10.1128/microbiolspec.BAD-0003-2016

Bailey, N. T. J. (1959). Statistical Methods in Biology. London: The English Universities Press Ltd.

Bartual, S. G., Seifert, H., Hippler, C., Luzon, M. A., Wisplinghoff, H., and Rodríguez-Valera, F. (2005). Development of a multilocus sequence typing scheme for characterization of clinical isolates of Acinetobacter baumannii. J. Clin. Microbiol. 43, 4382-4390. doi: 10.1128/JCM.43.9.4382-4390.2005

Botstein, D. (1980). A theory of modular evolution for bacteriophages. Ann. N.Y. Acad. Sci. 354, 484-490.

Clokie, M. R. J., Kropinski, A. M., and Lavigne, R. (2018). "Bacteriophages methods and protocols," in Methods in Molecular Biology, Vol. 3 (New York, NY: Springer Nature).
2017M3A9B8069292, ATC Program 10076996 from Ministry of Trade, Industry, and Energy of Korea, and HUFS Research Fund of 2017.

\section{SUPPLEMENTARY MATERIAL}

The Supplementary Material for this article can be found online at: https://www.frontiersin.org/articles/10.3389/fmicb. 2018.00696/full\#supplementary-material

Supplementary Figure 1 | Histamine levels in sera from mice treated with phages using three different routes, intraperitoneal (i.p), intranasal (i.n), or oral (p.o). The experiment was performed in triplicate. ${ }^{*} p<0.05$, ${ }^{* *} p<0.01$.

Clokie, M. R. J., and Kropinski, A. M. (2009a). "Bacteriophages methods and protocols," in Methods in Molecular Biology, Vol. 1 (New York, NY: Springer Nature).

Clokie, M. R. J., and Kropinski, A. M. (2009b). "Bacteriophages methods and protocols," in Methods in Molecular Biology, Vol. 2 (New York, NY: Springer Nature).

Davies, R. L., and Lee, I. (2006). Diversity of temperate bacteriophages induced in bovine and ovine Mannheimia haemolytica isolates and identification of a new P2-like phage. FEMS Microbiol. Lett. 260, 162-170. doi: 10.1111/j.1574-6968.2006.00314.x

Dijkshoorn, L., Nemec, A., and Seifert, H. (2007). An increasing threat in hospitals: multidrug-resistant Acinetobacter baumannii. Nat. Rev. Microbiol. 5, 939-951. doi: 10.1038/nrmicro1789

Doi, Y., Murray, G. L., and Peleg, A. Y. (2015). Acinetobacter baumannii: evolution of antimicrobial resistance-treatment options. Semin. Respir. Crit. Care Med. 36, 85-98. doi: 10.1055/s-0034-1398388 
García-Quintanilla, M., Pulido, M. R., López-Rojas, R., Pachón, J., and McConnell, M. J. (2013). Emerging therapies for multidrug resistant Acinetobacter baumannii. Trends Microbiol. 21, 157-163. doi: 10.1016/j.tim.2012.12.002

Hua, Y., Luo, T., Yang, Y., Dong, D., Wang, R., Wang, Y., et al. (2018). Phage therapy as a promising new treatment for lung infection caused by carbapenem-resistant Acinetobacter baumannii in mice. Front. Microbiol. 8:2659. doi: $10.3389 /$ fmicb.2017.02659

Huang, T. W., Lauderdale, T. L., Liao, T. L., Hsu, M. C., Chang, F. Y., Chang, S. C., et al. (2015). Effective transfer of a $47 \mathrm{~kb}$ NDM-1-positive plasmid among Acinetobacter species. J. Antimicrob. Chemother. 70, 2734-2738. doi: $10.1093 / \mathrm{jac} / \mathrm{dkv} 191$

Huys, I., Pirnay, J.-P., Lavigne, R., Jennes, S., De Vos, D., Casteels, M., et al. (2013). Paving a regulatory pathway for phage therapy. EMBO Rep. 14, 951-954. doi: 10.1038/embor.2013.163

Hyman, P., and Abedon, S. T. (2009). Practical methods for determining phage growth parameters. Methods Mol. Biol. 501, 175-202. doi: 10.1007/978-1-60327-164-6_18

Jeon, J., D'Souza, R., Pinto, N., Ryu, C. M., Park, J., Yong, D., et al. (2016a). Characterization and complete genome sequence analysis of two myoviral bacteriophages infecting clinical carbapenem-resistant Acinetobacter baumannii isolates. J. Appl. Microbiol. 121, 68-77. doi: 10.1111/jam.13134

Jeon, J., Ryu, C. M., Lee, J. Y., Park, J. H., Yong, D., and Lee, K. (2016b). In vivo application of bacteriophage as a potential therapeutic agent to control OXA-66-Like carbapenemase-producing Acinetobacter baumannii strains belonging to sequence ype 357. Appl. Environ. Microbiol. 82, 4200-4208. doi: 10.1128/AEM.00526-16

Keller, B., Dubochet, J., Adrien, M., Maeder, M., Wurtz, M., and Kellenberger, E. (1988). Length and shape varients of bacteriophage T4 head: mutations I scaffolding core genes 68 and 22. J. Virol. 62, 2960-2969.

Kim, M. S., Hong, S. S., Park, K., and Myung, H. (2013). Genomic analysis of bacteriophage PBECO4 infecting Escherichia coli O157:H7. Arch. Virol. 158, 2399-2403. doi: 10.1007/s00705-013-1718-3

Krahn, T., Wibberg, D., Maus, I., Winkler, A., Bontron, S., Sczyrba, A., et al. (2016). Intraspecies transfer of the chromosomal Acinetobacter baumannii blaNDM-1 carbapenemase gene. Antimicrob Agents Chemother. 60, 3032-3040. doi: 10.1128/AAC.00124-16

Kröger, C., Kary, S. C., Schauer, K., and Cameron, A. D. (2017). Genetic regulation of virulence and antibiotic resistance in Acinetobacter baumannii. Genes 8:12. doi: $10.3390 /$ genes 8010012

Kropinski, A. M., Mazzocco, A., Waddell, T. E., Lingohr, E., and Johnson, R. P. (2009). Enumeration of bacteriophages by double agar overlay plaque assay. Methods Mol. Biol. 501, 69-76. doi: 10.1007/978-1-60327-164-6_7

Kusradze, I., Karumidze, N., Rigvava, S., Dvalidze, T., Katsitadze, M., Amiranashvili, I., et al. (2016). Characterization and testing the efficiency of Acinetobacter baumannii phage vB-GEC_Ab-M-G7 as an antibacterial agent. Front Microbiol. 7:1590. doi: 10.3389/fmicb.2016.01590

Lee, C.-R., Lee, J. H., Park, M., Park, K. S., Bae, I. K., Kim, Y. B., et al. (2017). Biology of Acinetobacter baumannii: pathogenesis, antibiotic resistance mechanisms, and prospective treatment options. Front. Cell. Infect. Microbiol. 7:55. doi: $10.3389 /$ fcimb.2017.00055

Li, E., Zhao, J., Ma, Y., Wei, X., Li, H., Lin, W., et al. (2016). Characterization of a novel Achromobacter xylosoxidans specific siphoviruse: phiAxp-1. Sci. Rep. 6:21943. doi: 10.1038/srep21943

Lin, D. M., Koskella, B., and Lin, H. C. (2017). Phage therapy: an alternative to antibiotics in the age of multi-drug resistance. World J. Gastrointest. Pharmacol. Ther. 8, 162-173. doi: 10.4292/wjgpt.v8.i3.162

McConnell, M. J., Actis, L., and Pachon, J. (2013). Acinetobacter baumannii: human infections, factors contributing to pathogenesis and animal models. FEMS Microbiol. Rev. 37, 130-155. doi: 10.1111/j.1574-6976.2012.00344.x

Merabishvili, M., Vandenheuvel, D., Kropinski, A. M., Mast, J., De Vos, D., Verbeken, G., et al. (2014). Characterization of newly isolated lytic bacteriophages active against Acinetobacter baumannii. PLoS ONE 9:e104853. doi: 10.1371 /journal.pone. 0104853
Mihu, M. R., and Martinez, L. R. (2011). Novel therapies for treatment of multidrug resistant Acinetobacter baumannii skin infections. Virulence 2, 97-102 doi: 10.4161/viru.2.2.15061

Parasion, S., Kwiatek, M., Gryko, R., Mizak, L., and Malm, A. (2014). Bacteriophages as an alternative strategy for fighting biofilm development. Pol. J. Microbiol. 63, 137-145.

Park, K., Cha, K. E., and Myung, H. (2014). Observation of inflammatory responses in mice orally fed with bacteriophage T7. J. Appl. Microbiol. 117, 627-633. doi: 10.1111/jam.12565

Regeimbal, J. M., Jacobs, A. C., Corey, B. W., Henry, M. S., Thompson, M. G., Pavlicek, R. L., et al. (2016). Personalized therapeutic cocktail of wild environmental phages rescues mice from Acinetobacter baumannii wound infections. Antimicrob. Agents Chemother. 60, 5806-5816. doi: 10.1128/AAC.02877-15

Sambrook, J., and Russell, D. W. (2006). Purification of bacteriophage $\lambda$ particles by centrifugation through a glycerol step gradient. Cold Spring Harb. Protoc. 2006:pdb.prot3969. doi: 10.1101/pdb.prot3969

Schooley, R. T., Biswas, B., Gill, J. J., Hernandez-Morales, A., Lancaster, J., Lessor, L., et al. (2017). Development and use of personalized bacteriophagebased therapeutic cocktails to treat a patient with a disseminated resistant Acinetobacter baumannii infection. Antimicrob. Agents Chemother. 61:e0095417. doi: 10.1128/AAC.00954-17

Shivaswamy, V. C., Kalasuramath, S. B., Sadanand, C. K., Basavaraju, A. K., Ginnavaram, V., Bille, S., et al. (2015). Ability of bacteriophage in resolving wound infection caused by multidrug-resistant Acinetobacter baumannii in uncontrolled diabetic rats. Microb. Drug Resist. 21, 171-177. doi: $10.1089 / \mathrm{mdr} .2014 .0120$

Tuon, F. F., Rocha, J. L., and Merlini, A. B. (2015). Combined therapy for multidrug-resistant Acinetobacter baumannii infection - is there evidence outside the laboratory? J. Med. Microbiol. 64, 951-959. doi: 10.1099/jmm.0.000144

Turner, D., Wand, M. E., Briers, Y., Lavigne, R., Sutton, J. M., and Reynolds, D. M. (2017). Characterisation and genome sequence of the lytic Acinetobacter baumannii bacteriophage vB_AbaS_Loki. PLoS ONE 12:e0172303. doi: 10.1371/journal.pone.0172303

Wang, Y., Mi, Z., Niu, W., An, X., Yuan, X., Liu, H., et al. (2016). Intranasal treatment with bacteriophage rescues mice from Acinetobacter baumanniimediated pneumonia. Fut. Microbiol. 11, 631-641. doi: 10.2217/fmb.16.11

Weber, B. S., Harding, C. M., and Feldman, M. F. (2016). Pathogenic Acinetobacter: from the cell surface to infinity and beyond. J. Bacteriol. 198, 880-887. doi: 10.1128/JB.00906-15

Yang, H., Liang, L., Lin, S., and Jia, S. (2010). Isolation and characterization of a virulent bacteriophage $\mathrm{AB} 1$ of Acinetobacter baumannii. BMC Microbiol. 10:131. doi: 10.1186/1471-2180-10-131

Zhang, G., Leclercq, S. O., Tian, J., Wang, C., Yahara, K., Ai, G., et al. (2017). A new subclass of intrinsic aminoglycoside nucleotidyltransferases, ANT(3")II, is horizontally transferred among Acinetobacter spp. by homologous recombination. PLoS Genet. 13:e1006602. doi: 10.1371/journal.pgen.10 06602

Zhang, J., Liu, X., Li, and Li, X. J. (2015). Bioinformatic analysis of phage AB3, a phiKMV-like virus infecting Acinetobacter baumannii. Genet. Mol. Res. 14, 190-198. doi: 10.4238/2015

Conflict of Interest Statement: The authors declare that the research was conducted in the absence of any commercial or financial relationships that could be construed as a potential conflict of interest.

Copyright $\odot 2018$ Cha, Oh, Jang, Jo, Kim, Ha, Ko and Myung. This is an open-access article distributed under the terms of the Creative Commons Attribution License (CC $B Y)$. The use, distribution or reproduction in other forums is permitted, provided the original author(s) and the copyright owner are credited and that the original publication in this journal is cited, in accordance with accepted academic practice. No use, distribution or reproduction is permitted which does not comply with these terms. 